\title{
Exchanges and Peacemaking: Counterfactuals and Unexplored Possibilities
}

\author{
Iain Wilson \\ University of Edinburgh
}

\begin{abstract}
We may expect international exchange programmes to contribute to peaceful international relations, but how strong is the evidence that they actually do? In addition to the intercultural education discussed elsewhere in this issue, I classify mechanisms by which exchanges might contribute to peace into four categories - signaling, attitude change, network formation and institutional transfer - and assess the evidence that exchanges affect international relations through each of these mechanisms. Despite considerable research there are still important gaps in the evidence, and these gaps may have significant consequences for how we organize exchanges and what kinds of mobility we support.
\end{abstract}

Keywords: International exchange programmes, peace, research evidence, institutions, learning

\section{Introduction}

International exchange programmes have been treated as means to political ends for hundreds of years. ${ }^{1}$ Nonetheless, there are many gaps in our understanding of how exchanges influence international relations and how they might contribute to that most elusive of political goals: peace. In this article I sketch some of the most popular mechanisms by which exchanges are expected to influence international politics, and suggest that we need more evidence on whether they allow exchange programmes to fulfill the - often quite dramatic - expectations policymakers often have for exchanges. ${ }^{2}$ Many of the authors in this issue are private advocates for greater international mobility, and making a case for public support of such mobility requires us to identify public benefits. Linking exchanges with peace establishes a clear public benefit, but advocacy is necessarily stronger when it is backed by stronger evidence. Tying cause to effect when it comes to exchanges and international relations is surprisingly challenging.

\section{Benefits to Individuals versus Public Goods}

Probably the most important qualification to make here is that this paper deals only with the link between exchanges and peace. This should not be taken to imply that the impact of mobility

\footnotetext{
Iain Wilson, Chrystal Macmillan Fellow, Politics and International Relations, University of Edinburgh. Email: iwilson@ laurentian.ca.

1 Richard Arndt. The First Resort of Kings (Dulles: Potomac, 2005).

2 Iain Wilson, "Political Expectations," in International Exchange Programs and Political Influence: Manufacturing Sympathy? (New York: Palgrave Macmillan, 2014), 9-19; Iain Wilson, "Ends Changed, Means Retained: Scholarship Programs, Political Influence and Drifting Goals," British Journal of Politics and International Relations 17, no.1 (2015): 130-51.
} 
on international relations is more important than the other consequences. The evidence that mobility brings other benefits is much more clear-cut. There can be enormous educational, social, cultural and career benefits from studying abroad to individual exchangees, which are well-documented. ${ }^{3}$ Spending time abroad at critical points of personal and intellectual development clearly has a huge impact on many individual students' lives, with effects which go beyond just the impact of studying (which would also have occurred had they stayed in their home countries).

We might, of course, choose to believe that these kinds of benefits to individuals will almost by definition filter through to positive outcomes for society as a whole, and that this is sufficient reason to devote resources to exchange programmes. This is, after all, a popular rationale for public support of higher education generally, and might well be sufficient to endorse the relatively modest costs of promoting student mobility. Nonetheless, the question of how we can show a link between exchanges and peace - or if one even exists - is a distinct and much more intellectually challenging one. This challenge has the added bonus of being extremely interesting - and how analysts have attempted to answer it reveals a great deal about the technologies of governance.

\section{Five Potential Links to Peace}

The existing literature suggests four major effects of student mobility which might contribute to peace: signaling, attitude change, intercultural competence, and network formation. These mechanisms are implicit in a lot of the rhetoric surrounding exchange programmes, and also feed into the criteria by which governments which allocate funding to exchanges evaluate their impact. ${ }^{4}$ However, the popularity of a claim does not make it true. The existing empirical evidence that exchange programmes signal goodwill, change attitudes, train informal mediators, and produce long-term networks, and that these then contribute to peace, is far from watertight. We have a great opportunity to strengthen it.

I also want to propose a fifth and distinct mechanism by which exchanges might affect the prospects for peace, the transfer of governmental institutions between countries. This has been foreshadowed by administrators of several exchange programmes, especially the injection of significant funds into Eastern Europe to promote exchanges following the collapse of the Iron Curtain. However, that section of the paper offers a development of the theory behind those policy intuitions.

\subsection{Signaling}

Perhaps the most obvious political impact of exchange programmes is not directly related to exchangees at all. Inviting foreign nationals into a country under benign circumstances can have a healthy symbolism. By committing to host foreign visitors for years to come, and by sending impressionable young elites to live in a foreign country, government officials are signaling to their counterparts in a foreign country that they expect their two countries to enjoy peaceful, benevolent relations in the future. Creating exchange programmes can

See e.g. Elizabeth Murphy-Lejeune, Student Mobility and Narrative in Europe (London: Routledge, 2002); Iain Wilson, International Exchange Programs, 139-93.

4 Iain Wilson, "Can We Infer That Mobility Has Political Impact? Some Historical Case Studies," in International Exchange Programs, 19-47. 
also communicate this expectation to wider civil society in both countries, as launches of exchange programs are typically well-publicized. Senior decision-makers are often pictured smiling for the cameras with foreign visitors, sign press releases, and so on. This signaling function falls within the familiar paradigm of "high diplomacy"s in which the interaction between states' elite decision-makers is all-important. From this perspective, exchanges matter because they help those elites to guess what their opposite numbers are thinking and help to smooth their social interactions. The people who actually travel abroad, and the more humble administrators who really facilitate their travel and make smaller policy decisions, seem almost incidental.

I have no reason to doubt that exchanges can have a symbolic impact, and that creating them may help politicians and diplomats communicate pacific intentions in ways that mere rhetoric cannot. But it is important to realize that this kind of impact is quite seriously selflimiting. Because this image of diplomacy is dominated by current elites (ambassadors, government ministers and so on) the students themselves are simply objects of exchange who do not play much of an active role in the relationship between the two countries. The main link to peace is that creating exchange programmes is part of a ritual through which elite policymakers in one country convince others that they really want to improve a relationship. From this perspective, those officials' very visible public associations with the launch are vital to an exchange programme's diplomatic function. Unfortunately, top decision-makers are busy people with only finite amounts of time to devote to any given relationship. They may be nominally responsible for many different exchanges, in addition to all of their other duties. And, of course, turnover among elites means that the minister who launches any programme will probably be gone within a few years, while an exchange may persist for much longer. Consequently, it is not realistic to expect top decision-makers to be personally involved in overseeing exchange programmes. They soon become routinized, administered by relatively junior functionaries who have little influence on high-level foreign policy, and decoupled from the very top decision-makers. Hence the signaling effect will be important at the creation of an exchange programme but much less potent when it has been running for a long time - although there might be costs to terminating an existing exchange.

Furthermore, my research has shown that in practice governments can launch student mobility programs for even more short-term reasons. In "Ends Changed, Means Retained," 6 I explore the history of three major scholarship programs disbursing public funding to successful foreign students aiming to study in the UK: the Marshall, Commonwealth and Chevening Scholarships. Each of these now has declared diplomatic ambitions, typically linked to the future careers of their alumni. But digging into their records revealed that they were actually set up to smooth relationships with foreign governments Britain had managed to offend in some way, avoiding diplomatic embarrassment in the short term. The Marshall Scholarships were offered to the USA as symbolic thanks for postwar Marshall Aid, but only after the Foreign Office had discovered that the gift the Americans really seemed to want - an original manuscript of the Magna Carta - could not be released. Commonwealth Scholarships were proposed by the Canadian delegation to a major international conference as part of a large package of ideas which the British Government perceived as risky and expensive, and spending a relatively small amount of money supporting the scholarships was

5 David Mayers, The Ambassadors and America's Soviet Policy (Oxford: OUP, 1996), 3-4.

6 Wilson, "Ends Changed," 130-51. 
seen as a way of softening the rejection. The Chevening Programme - which has now grown into a comprehensive scholarship programme, roughly a British equivalent of Fulbright - has developed from a fund designed to offset a steep increase in tuition fees for Commonwealth students attending British universities. Commonwealth governments, whose students had become accustomed to cheap tuition in the UK, were upset when Britain removed a subsidy in the early 1980s. The scholarships were intended to distract them from this irritation. In each case the Foreign Office facilitated student mobility not so much as a self-conscious signal to foreigners as to distract attention from an embarrassing situation in which there was a risk of offending dignitaries. Any impact created by the students themselves was incidental.

Perhaps the most famous example of a cultural exchange being used to transmit signals at elite level is the 'ping-pong diplomacy' between China and the USA which led up to Nixon's visit to China. This was an excellent example of a cultural exchange being used as a signal of intent. Although American officials had been in surreptitious contact with the Chinese for some time, the public invitation of an American ping-pong team to China did open new diplomatic channels, and opened the relationship to view by the general public in both countries. But, as Griffin makes clear, the diplomatic importance of the ping-pong tour lay in the personal engagement of Chinese leaders, especially Zhou En-Lai who met personally with the visitors. ${ }^{7}$ Although the meetings between athletes were staged to seem like spontaneous people-to-people contact, they were actually carefully orchestrated by the Chinese government. The Chinese ping-pong players had very little agency, but were controlled by politicians - this was what made the signals so potent. Chinese elites were using private citizens who crossed international borders to signal their intentions to their American counterparts.

Creating exchanges may play a role in high diplomacy, with the people who actually travel abroad symbolic pawns in elite interactions. This is a familiar paradigm for international diplomacy. Nonetheless, over the years considerations of how exchanges can contribute to peace have tended to expand out from this putative signaling function. Where exchange programs are underwritten by foreign ministries, they are often evaluated in terms of attitude change.

\subsection{Attitude change}

In 2008 the British Foreign Secretary removed Foreign Office funding from the Commonwealth Scholarship and Fellowship Plan. The Foreign Office contribution had helped mainly postgraduate students from wealthier Commonwealth countries to study in the UK. His reasoning for this was intriguing.

We propose a smaller, better organised programme, focused on the leaders of tomorrow, from a wide range of backgrounds... We will select more carefully to ensure our scholars really are potential future leaders, with our heads of mission having personal responsibility for ensuring their posts are getting this right. ${ }^{8}$

Aside from the open question of how ambassadors were to be held responsible for selecting future leaders who will not reach their potential until long after those ambassadors had retired, this raises the question of why 'leadership' is so important, and what it actually means. 
Some exchange programs involve very large numbers of participants. Typically these are genuine exchange programs, in which participants from one country literally swap places with participants from another. This design has a very long history for exchanges of school-age children, and it can be relatively cheap. If an American family is educating a teenager already, the costs of swapping him for a Turkish teenager for a few weeks are limited. However, most exchanges do not work that way, and for good reason. Strict exchanges suffer from most of the drawbacks of a barter economy. A straight swap is limited to situations where there is equal demand to go abroad in the two countries, and where there is adequate support already in place. If many Americans wish to visit Turkey but few Turks are willing to go to America, some of those Americans are going to be disappointed. There is always a risk of missing a future leader. Hence, many of the more familiar mobility programmes are actually what I term "pseudo-exchanges" in which new spaces are created, and funded, especially for a foreign visitor. The various iterations of the Fulbright Program offer good examples. Fulbright visitors to the USA are not displacing Americans, but the funding behind them allows universities, colleges, schools, offices and studios to open extra places designated for Fulbrighters.

Over the years, this method of facilitating mobility has allowed an international competition to develop, with countries seeking to attract the most promising students and young professionals. It has become possible for talented individuals to spend several years abroad, funded by foreign governments in the expectation that they will be useful allies in the future. Supporting them can become quite expensive for the host, so these programs rarely involve huge numbers of individuals. Given that international peace is a function of states rather than individuals, the impact on this relatively small number of individuals needs to be amplified by some kind of "multiplier effect" to affect the behavior of their state. There are basically two ways in which the impact of changed attitudes could be multiplied. Either alumni go on to become disproportionately powerful themselves, for example being elected to high office or holding top civil service positions (what I call the "elite multiplier") or they have disproportionate influence on public opinion (for example, they become journalists, socialites or even teachers). As Giles Scott-Smith explains, from quite a critical perspective, this can be traced to an 'opinion-leader model' which has come to implicitly underpin the arguments for spending public money on most exchange programmes. ${ }^{10}$ In the opinionleader model, returning students go on to shape mass public opinion about their former hosts, shaping the behavior of their country as a whole.

Both of these multipliers seem to rely on prior attitude change. The opinion leader model implies that exchanges change exchangees' attitudes to foreign countries. Through multiplication, these changed attitudes among individuals go on to affect how the country as a whole relates to others, leading - theoretically - to improved international relations and prospects for peace.

\subsubsection{State of the evidence}

In my past work I have questioned whether living abroad actually has the kind of consistent impact on exchangees' attitudes that we might expect from simple intuition. I have no doubt

\footnotetext{
9 Michael Smith, "Educational Leadership for a Free World," The Teachers College Record 57, no.5 (1956): $285-89$.

10 Giles Scott-Smith, "Mapping the Undefinable," Annals of the Academy of Social Science 616, no.1 (2008): 173-95
} 
that some exchangees do return home with positive attitudes to the host country, but this information is not particularly helpful when we come to think about the broader impact of exchanges on peace. While international peace clearly has something to do with individual agency, it is far from sufficient to assume that attitude change at an individual level leads to peace. For one thing, even if some individuals do become more positive they may be counterbalanced by others who become disillusioned. And it is surprisingly difficult to establish a cause and effect relationship behind positive attitudes. People rarely recall their attitudes from even a few months ago with much accuracy, and usually struggle to explain what caused any changes in their attitudes, so the fact that they are positive now may reflect earlier socialization.

As I have explained in detail elsewhere, ${ }^{11}$ until a few years ago there were some quite serious methodological problems in academic studies purporting to test the opinion-leader model. There was a real need for before-and-after tracking of participants, to get an accurate impression of whether their attitudes had really changed. We had no studies which both measured the attitudes of large groups before-and-after and compared exchangees with control groups of non-exchange students. Only before-and-after studies could show that net change was taking place at an aggregate level, and control groups would be needed to show that fluctuating attitudes did not simply reflect shifts in public opinion which had nothing to do with individuals' mobility.

Having identified this gap in the evidence, Emanual Sigalas and I independently conducted such studies and found surprisingly little evidence that attitudes systematically become more positive. ${ }^{12}$ Some exchangees returned with more positive attitudes than when they left home, but the changes were usually modest and were balanced out by others moving in the opposite direction. This might suggest that we will be disappointed if we conceptualize the impact of exchanges solely in terms of attitude change.

Before we jump to that conclusion, it is worth pointing out a few caveats. Firstly, this empirical evidence suffers from a Eurocentric bias. For good practical reasons investigators have focused on mobility within 'the West', particularly on the European Erasmus Programme. But we can easily imagine that mobility across greater cultural distances and from more restrictive political systems, which actively conceal information about the outside world from their citizens, could have a much greater impact on attitudes. In fact, the practical difficulties of recruiting students mean that respondents tend to come overwhelmingly from particular countries even within Europe. In a recent article in the Journal of Common Market Studies, Kristine Mitchell presents evidence which questions both my findings and Emmanual Sigalas'. ${ }^{13}$ Both of our studies involved large numbers of Erasmus students moving between the UK and mainland Europe, and she suggests that there may be something about Britain which fails to promote Europhilia. We cannot simply dismiss this possibility since we know that the impact of mobility is generally contingent on circumstances. ${ }^{14}$ In fact, Mitchell's findings underline our shared view that the question of whether and how exchanges affect

11 Wilson, International Exchange Programs, 47-59.

12 Emanual Sigalas, "Cross-Border Mobility and European Identity," European Union Politics 11, no.2 (2010): 241-65; Iain Wilson, "What Should We Expect of 'Erasmus Generations'?” JCMS: Journal of Common Market Studies 49, no.5 (2011): 1113-40; Wilson, International Exchange Programs, 87-175.

13 Kristine Mitchell, "Rethinking the 'Erasmus Effect' on European Identity," Journal of Common Market Studies 53, no.2 (2015): 330-48; Wilson, "What Should We Expect,"; Wilson, International Exchange Programs; Sigalas, "Cross-Border Mobility".

14 Yehuda Amir, "The Contact Hypothesis in Ethnic Relations," Psychological Bulletin 71, no.5 (1969): 319-42. 
political attitudes is a complex one which probably does not have one simple answer. We need to know much more about the social contexts within which exchanges take place before we can predict what kinds of attitude change any given sojourn may produce. We cannot assume that simple exposure to other cultures will consistently lead to desirable attitudes.

If assumptions about short-term impact are uncertain, then it becomes even more troublesome to find out whether positive attitudes provoked by exchanges will endure over the years. We still have limited evidence about the long-term impact of exchanges on attitudes, partly because we rarely have baseline measures of their political attitudes before they travel and partly because it is so hard to keep track of large groups of alumni over time. We do know that attitudes to a former host country are fixed rather than fluid, and even long after the exchangee returns home those experiences are reinterpreted in light of subsequent events. Gullahorn and Gullahorn and Murphy-Lejeune demonstrate that there are patterns in how exchangees' attitudes to their hosts fluctuate, but these are complicated and attitudes definitely do not remain constant over time, either while abroad or after returning home. ${ }^{15}$ Typically, visitors tend to have very positive attitudes when they arrive, these degenerate over time in the face of everyday frustrations, and they then become more positive as they approach the end of their stay. On their return home, Gullahorn and Gullahorn suggest that exchangees experience a second emotional U-curve, in which short-lived euphoria at returning to a familiar culture is replaced by 'reverse culture shock' followed by a gradual re-acclimatization to the home country. We do not know for sure how these predictable attitudes to the home country might be reflected in attitudes to the former host, but it seems logical to expect some effect. On the other hand, the length (in time) of these curves may be idiosyncratic. This poses yet another challenge for attempts to measure attitude change, as we cannot know where in the re-entry curve respondents may be and how this could be distorting their opinion of the host country. However, it does seem like we cannot be confident that long-term attitudes to the host will be reflected in attitudes a few weeks after returning home - but for obvious practical reasons existing before-and-after surveys measure attitudes soon after returning home.

Despite all of these uncertainties about the long-term impact of exchanges on attitudes, to my knowledge no existing studies track systematic samples of alumni over decades. Instead, our evidence about the long-term impact of mobility usually comes from interviews with alumni who are keen to communicate with researchers or scheme administrators. It should not come as a surprise that these alumni tend to report positive attitudes, since they are largely self-selecting. ${ }^{16}$

\subsubsection{Differential multiplication}

Traditionally, measurements of attitude change in populations such as exchange students have followed this simple quantitative logic. If more alumni developed positive attitudes than negative attitudes, weighted for the intensity of attitude change, then that would be considered a positive outcome; if more alumni developed negative than positive attitudes, then that would be considered a negative outcome. But this seems to miss some of the complexity of social interactions: not all attitude changes necessarily have equal practical

15 John Gullahorn and Jeanne Gullahorn, “An Extension of the U-curve Hypothesis,” Journal of Social Issues 19, no.3 (1963): 33-47; Murphy-Lejeune, Student Mobility.

16 Wilson, International Exchange Programs, 47-59. 
impact. There is one other possibility to which none of us seems to be doing justice at the moment: multiplication may differ depending on the direction of attitude change. This is something I see as at least a theoretical possibility, but one which is completely untested.

Even if experimental designs reveal that the numbers of exchangees who develop positive attitudes are balanced by others who become more negative, it is possible that the positive alumni systematically go on to become more influential than the negative alumni. In this case, the multiplication of positive changes would be much more dramatic than the multiplication of negative changes. Perhaps positive alumni are inspired by their experiences and at a statistical level they have a tendency to go on to influential, internationally-oriented careers - while the others deliberately avoid international relations and therefore have little influence over them. Without long-term, systematic tracing of a large number of alumni - not skewed toward those enthusiastic alumni who take pains to stay in touch - we simply do not know if different kinds of attitudes are multiplied to the same degree.

\subsection{International Networks}

Even if their attitudes to the host country did not change significantly, exchangees could develop enduring links with the country they visited. There are two possibilities: exchanges may increase cultural competence and form social networks.

\subsubsection{Competence}

Cultural competence refers to individuals' feeling of comfort dealing with nationals of their former host country. The experience of being immersed in another culture might also increase exchangees' comfort in dealing with foreigners more generally or endow them with intercultural competence which is not specific to the host country they actually visited. Either of these might lubricate relationships between countries into the distant future and facilitate communication across borders. Again, however, there are open research agendas around the impact of exchange mobility on (inter)cultural competence, and on the kinds of contextual factors which might promote such competence among mobile individuals. Several of the contributors to this issue have a much deeper background on these issues than I can offer, and their analyses offer insights into both the role of exchanges in intercultural competence and the long-term consequences.

However, it is useful to reflect here on how (inter)cultural competence might fit into the political impact of exchanges within international relations. If international conflict is sometimes caused by a failure of states to appreciate different views of an issue, then accurate communication in critical situations may reduce tensions and this could be very important for the prospects of peace. Clearly, communication relies on much more than just vocabulary and grammar, but requires some level of overlapping cultural competence. Again, the direct impact will be on relatively small numbers of exchangees. In order for changes in a small number of people to affect international relations, they would need to either communicate those changes to many others or else go on to become disproportionately influential themselves (for example, as professional diplomats at the formal interface between societies). Theoretically, increasing competence among either the whole population, such that the general public push for more appropriate action towards foreign countries, or among elites in a position to directly influence government policy, could be important if exchangees 
return with greater communicative competence and the changes in those individuals are multiplied up to affect international politics. Yet another possibility is that a combination of mobility and cultural competence helps people to for and sustain relationships with specific individuals in foreign countries, which in turn influences international politics.

\subsubsection{Networks}

Exchanges might contribute to peace by creating helpful social networks across national borders. The difference between this mechanism and cultural competence is that the intermediate step is a specific set of social linkages with individuals in a foreign country, rather than a more generic ability to interrelate with foreigners in general. Most obviously, exchangees might form influential networks while they are living abroad. The intuition here is that visitors from abroad meet many people they would never have encountered had they stayed at home, and that they will form ongoing relationships with some of them. These relationships will enable them to exchange favors or information or simply socialize into the future, keeping lines of informal communication between the two countries open.

As with intercultural competence, exchanges could contribute to the formation of networks with the host country but might also tie exchangees to third countries. This is reassuring since many exchangees seem to have quite limited contact with host nationals. University scholarships in particular can enable visitors to live in multicultural bubbles inside the host country, meeting largely other visitors from similar backgrounds. ${ }^{17}$ But this does not mean their networks could not have significant effects on peace by binding countries together. Peace is not always simply a function of relations between State A and State B: a situation where $\mathrm{B}$ is allied with $\mathrm{C}$, but $\mathrm{A}$ and $\mathrm{C}$ have strained relations, can be troublesome for all of them.

Unsurprisingly, we do have reasonably strong evidence that exchangees form different kinds of relationships than they otherwise would while they are abroad. ${ }^{18}$ This is a necessary condition for exchange-facilitated networks to contribute to peace, but far from a sufficient one. Again, exchangees are rarely in a position to have much influence on international relations while they are abroad - the issue is whether the networks they establish in the present will be important in the future. Unfortunately, the evidence is less clear on the long-term impact of networks, on the scale of networking attributable to exchanges, and particularly on how they compare with the counterfactual. Do exchangees establish more powerful networks than they would have built up anyway had they remained in their home countries?

We can know that short-term networks are built up while exchangees are abroad. We might also point to anecdotes of such relationships sometimes being significant in international relations years later. Again, systematic tracing of alumni would strengthen our evidence. But such long-term tracing would not, in this case, be sufficient to address the counterfactual. If we understand networks as consisting of ongoing social contact with fellow alumni, it is possible to ask alumni whether they have ongoing contact; my experience of interviewing longstanding alumni suggests that some of them lose contact surprisingly quickly and it is difficult to locate influential linkages decades later. ${ }^{19}$ But this seems a rather narrow view of

\footnotetext{
17 Wilson, International Exchange Programs, 139-93.

18 See, Christof Van Mol and Joris Michielsen, "The Reconstruction of a Social Network Abroad," Mobilities 10, no.4 (2015): 423-44 (published electronically January, 21, 2014).

19 Wilson, International Exchange Programs, 175-93.
} 
how social networks operate, because it ignores latent networks. Put simply, latent networks are acquaintances, or acquaintances of acquaintances, of which we are not immediately conscious but who can prove very useful given the right circumstances. In fact, alumni themselves may not be able to estimate the impact of their networks: we can probably all come up with anecdotes about unexpectedly meeting former colleagues and classmates after losing touch for several years. These kinds of relationships might be very helpful in moments of tension, but by their very nature they are not easily quantifiable.

In other words, the difficulties of assessing how important networks formed by exchange programmes are do not simply reflect a lack of research. More fundamentally, there are epistemological problems we need to confront if we are to compare exchange programmes with a counterfactual in which students are not encouraged to go abroad. Again, anecdotes may suggest that networks traceable to exchanges can play a significant role in peacemaking, but we have less systematic evidence.

\subsection{Institution transfer and selection}

We know that exchanges could contribute significantly to peace through signaling (after they have been running for some time), attitude change, and network formation. Our information about how far each of these actually contributes is far from complete. But there is evidence that exchanges bring another benefit - one which could hypothetically be very significant for international politics. Mobility helps individuals to develop clear ideas about how public policies compare in different countries, which can contribute to changes in governance. Exchangees visiting another country see particular policy ideas in action, and come to think that some of these ideas might be implemented in their own country (and indeed vice versa). Visitors do not necessarily develop greater approval, and they seem just as likely to come away with a firm conviction that their country should avoid some possibilities they observe abroad. But their exposure does give them firm ideas about which alternatives they like and dislike. ${ }^{20}$

Perhaps more surprisingly, this knowledge seems to have an enduring effect on policy preferences in later life. In my interviews with longstanding alumni of elite scholarship programmes, those who went abroad many years earlier and returned to positions of prominence in their home countries, I was struck by their willingness to ascribe their support for specific policy ideas many years later, when they were established in their careers, to having seen similar policies in action while they were living abroad. The examples were often everyday, even banal - details of surgical services, town planning, bus timetables, and so on - but they were aspects of public policy the visitors would never have learned about had they not spent an extended period living relatively normal lives in the host country. In later life they pushed for elements of these policies to be implemented in their home countries. This advocacy was reflective and sensitive to local circumstances, but they were clear that their thinking had been heavily shaped by experience abroad - at least to the extent that they formed clear preferences where they had previously had none. ${ }^{21}$

Again, this finding comes with caveats. By their nature, these interviews give little sense of how common these kinds of policy changes are. They show only that policy change may

20 Wilson, International Exchange Programs.

21 Wilson, International Exchange Programs, 175-93. 
result from youthful participation. And their stories might underplay contextual factors which might have led former exchangees to converge on particular policies for other reasons. Again, we are discussing an implicit counterfactual. But it does seem intuitively plausible that being educated about practices overseas will affect someone's policy preferences, and there is a substantial body of evidence on international policy learning. ${ }^{22}$

Such policy changes may not seem hugely important on the global stage, and they usually affect aspects of public policy we rarely associate with war and peace. However, I suggest that they will have implications for state behavior, even though the consequences for international relations are very hard to predict.

My recent theoretical work has been applying Darwinian cultural selection theories to international politics. ${ }^{23}$ Cultural selection theories help to show why seemingly trivial changes in domestic policies can potentially affect the prospects of international peace.

Darwinian theories are characterized by an emphasis on systematic selection among diverse, and often unpredictable, competing traits spread within a population. Social evolutionary theories extend this logic to social evolution, in which ideas are the units of selection. In any large population of individuals there will be variation in the ideas they hold, and individuals holding different combinations of ideas will tend to behave differently under similar circumstances. Selection means that ideas which fit the environment in some way will be more likely to be copied into other minds and spread throughout the population, displacing competitors. But the individuals themselves are also subject to selection, some becoming influential (and able to spread or act on their views), some relegated to obscurity.

While biological selection is relatively straightforward (individuals either reproduce or do not, often as a result of being killed) the selective environment offered by society is rather different. Ideas and patterns of behavior constitute social institutions and these institutions themselves are selective environments. ${ }^{24}$

When we are considering international peace, the important question is not just how individuals behave but how large collectives (most obviously, states) behave toward each other. Many individuals have an influence on this, but some have more influence than others. Who ends up with most influence is largely a result of institutional selection.

For example, the institution of electoral politics results from a particular idea being widespread in society. It exists because enough people behave as if it does. We print individuals' names on pieces of paper, each mark one, count the pieces and then defer to the individual who received most marks. In order for elections to be meaningful, the idea of electoral politics has to get into enough minds. But once it has, elections become a means of selecting leaders, and will favor potential leaders with particular traits. They become part of the selective environment.

The formal process of selecting political leaders is an obvious example, but many other institutions go into sorting (or selecting) individuals into different positions in any society. For example, techniques for teaching languages may travel across borders, and they seem relatively innocuous. Yet in most societies political elites are drawn disproportionately from narrow and selective educational backgrounds. Having such a background may be treated

22 See e.g. Richard Rose, Learning from Comparative Public Policy (London: Routledge, 2005).

${ }^{23}$ Marion Blute, Darwinian Sociocultural Evolution (Cambridge: CUP, 2010); Peter Richerson and Robert Boyd, Not By Genes Alone (Chicago: University of Chicago, 2005); Iain Wilson, "Darwinian Reasoning and Waltz's Theory of International Politics," International Relations 27, no.4 (2013): 417-38.

24 Barry Barnes, The Nature of Power (Urbana: University of Illinois, 1988) 
as an implicit signal of electability if previous incumbents have been similarly qualified. Performing poorly on an examination which emphasized particular kinds of language skills could tip the balance.

Thinking about domestic politics in this way underlines that policy transfers, by altering the selective environment, will inevitably affect international relations.

This theory may be phrased rather unconventionally, but the essence of it should be quite familiar. Political analysts regularly refer, at least implicitly, to the selective effects of institutions. One example which has received a great deal of attention in the international relations literature is (Liberal) Democratic Peace Theory, which basically asserts that democracies are dramatically less likely to go to war with each other than autocracies. ${ }^{25}$ This particular argument has been challenged, probably with good reason, ${ }^{26}$ but it is an example of an explanation of foreign policy based on institutional selection. Democracies, proponents argue, punish particular behaviors associated with fighting wars and select out leaders who show them. Autocracies, by contrast, do not select so strongly against bellicosity because leaders do not need to appeal to a plurality of the whole population, merely an influential minority (such as military officers). A similar argument, intriguingly, can be found in the early work of Kenneth Waltz suggesting that he saw international politics as a set of selective systems nested within each other: the international system selects states which behave appropriately for prominence, ${ }^{27}$ but their internal institutions select the individuals who set their behavior. ${ }^{28}$ Such reasoning may even be implicit in US foreign policy and its emphasis on spreading democracy - not just because this is considered a good thing in itself, but because it is seen as a means to the end of promoting peace and ultimately the US national interest.

If this argument is acceptable when it comes to contrasting democracies with autocracies - and while the empirics may be debated, the mechanics of the argument have not been debunked - it seems reasonable that it should apply to other institutions as well. Many different institutions select personnel for different positions in society. Different selection and promotion strategies put different soldiers in command of armed forces, different education systems put different kinds of students in elite universities, different systems of healthcare funding allocate resources to different patients - and may or may not prioritize the potentially career-ending illnesses of future leaders. All of these will affect what kinds of people born into a diverse society will be in a position to influence international relations.

In other words, following this line of deduction it seems quite plausible that the right mix of institutions would promote pacificist behavior in a state. Transfers of policy ideas from one country to another should have some impact on state behavior and, ultimately, on the prospects for peace. Furthermore, the prospect of exchange programmes helping policymakers to come to more informed decisions does seem intuitively appealing.

Unfortunately, this particular mechanism may not be very helpful for promoters of exchange programmes. It seems as if any career must result from the complex concatenation

\footnotetext{
25 Immanuel Kant, Perpetual Peace (1795), accessed September 22, 2014, https:/www.mtholyoke.edu/acad/intrel/kant/ kant1.htm; Bruce Bueno de Mesquita, James Morrow, Randolph Siverson, and Alastair Smith, "An Institutional Explanation of the Democratic Peace," American Political Science Review 93, no.4 (1999): 791-807.

26 See, Michael Brown, Sean Lynn-Jones, and Stephen Miller, eds., Debating the Democratic Peace (Cambridge MA: MIT Press, 1996), 337-74.

27 Kenneth Waltz, Foreign Policy and Democratic Politics (Boston: Little, Brown, 1967).

28 Wilson, "Darwinian Reasoning".
} 
of many selective institutions, and this enormous complexity makes drawing inferences from selection a difficult proposition. The interactions among them mean that we cannot simply isolate one institution and pin the prospects for international peace on it, but we need to think about all of them interacting with each other. This implies an awesome amount of information. Unfortunately we cannot access a counterfactual by conducting controlled experiments, changing specific institutions to find out whether it improves or harms the odds of peaceful collaboration. This idea does suggest a mechanism by which exchanges could contribute to peace - through the intermediate step of promoting policy transfer - but it seems rather an unpredictable mechanism. Designing research which could link the two in particular cases would pose a formidable challenge.

Exchanges do educate individuals about how foreign countries are run. Sometimes this does affect governance in their home country (although I cannot show how common this is). Logically this will lead to different (kinds of) people being selected to make important decisions than otherwise would have been, and this should affect international relations. Unfortunately, institutional interactions are so complex that it would be excruciatingly difficult to predict which kinds of institutions would promote peacemaking. This means the relationship between policy learning and peace seems likely to remain a wildcard among the possible links between exchanges and peace, albeit an intriguing one.

\section{Conclusion}

There is still a surprising amount we do not know about the impact of exchange programs on international relations. There are both gaps in our empirical evidence, particularly when it comes to the long-term impact of mobility, and epistemological challenges. While we may find the idea that exchanges contribute to peace intuitively plausible - and probably most people who spend a lot of their time thinking about this question do - knowing more about the impact of exchanges would be reassuring.

This is an intriguing intellectual challenge, but addressing some of these gaps would have political significance as well. Exchanges are somewhat marginalized in foreign policy strategy, and certainly far fewer resources are devoted to exchange programs than to armaments. Clearer evidence linking mobility with the prospects for peace - if the link is actually a strong one - should help. Perhaps more importantly, the different possible mechanisms by which exchanges might contribute to peace imply that different designs of exchange programmes would be most effective. If signaling is the only effective link, then governments seeking peace should select exchangees so as to gain maximum attention among foreign leaders and maximum publicity. If the opinion leader model holds, they should aim for exchangees who will go on to be influential opinion-formers. If networking is the most important, then it makes sense to pick visitors who seem likely to be making influential decisions themselves in the future. And relatively obscure civil servants might play important roles as policy entrepreneurs if they are exposed to new ideas in their youth.

We now think about the impact of exchange programs quite differently than we did 65 years ago. Nonetheless, when it comes to linking exchanges and peace there are still important gaps. Filling these would be both conceptually and practically useful. This classic sociological question remains both challenging and intriguing. 


\section{Bibliography}

Amir, Yehuda. "The Contact Hypothesis in Ethnic Relations." Psychological Bulletin 71, no.5 (1969): 319-42.

Arndt, Richard. The First Resort of Kings. Dulles: Potomac, 2005.

Barnes, Barry. The Nature of Power. Urbana: University of Illinois, 1988.

Blute, Marion. Darwinian Sociocultural Evolution. Cambridge: CUP, 2010.

Brown, Michael, Sean Lynn-Jones, and Stephen Miller, eds. Debating the Democratic Peace. Cambridge MA: MIT Press, 1996.

Bueno de Mesquita, Bruce, James Morrow, Randolph Siverson, and Alastair Smith. "An Institutional Explanation of the Democratic Peace.” American Political Science Review 93, no.4 (1999): 791-807.

Griffin, Nicholas. Ping-Pong Diplomacy. New York: Scribner, 2014.

Gullahorn, John, and Jeanne Gullahorn. “An Extension of the U-curve Hypothesis.” Journal of Social Issues 19, no.3 (1963): 33-47.

Kant, Immanuel. Perpetual Peace. 1795. Accessed September 22, 2014. https://www.mtholyoke.edu/acad/intrel/ kant/kant1.htm.

Mayers, David. The Ambassadors and America's Soviet Policy. Oxford: OUP, 1996.

Mitchell, Kristine. "Rethinking the 'Erasmus Effect' on European Identity.” Journal of Common Market Studies 53, no.2 (2015): 330-48.

Murphy-Lejeune, Elizabeth. Student Mobility and Narrative in Europe. London: Routledge, 2002.

Richerson, Peter, and Robert Boyd. Not By Genes Alone. Chicago: University of Chicago, 2005.

Rose, Richard. Learning from Comparative Public Policy. London: Routledge, 2005.

Scott-Smith, Giles. "Mapping the Undefinable.” Annals of the Academy of Social Science 616, no.1 (2008): 173-95.

Sigalas, Emanual. "Cross-Border Mobility and European Identity." European Union Politics 11, no.2 (2010): 24165.

Smith, Michael. "Educational Leadership for a Free World.” The Teachers College Record 57, no.5 (1956): 285-89. Van Mol, Christof, and Joris Michielsen. "The Reconstruction of a Social Network Abroad.” Mobilities 10, no.4

(2015): 423-44. Published electronically January, 21, 2014

Waltz, Kenneth. Foreign Policy and Democratic Politics. Boston: Little, Brown, 1967.

Wilson, Iain. "Darwinian Reasoning and Waltz's Theory of International Politics." International Relations 27, no.4 (2013): 417-38.

—_ "Ends Changed, Means Retained: Scholarship Programs, Political Influence and Drifting Goals." British Journal of Politics and International Relations 17, no.1 (2015): 130-51.

_. International Exchange Programs and Political Influence: Manufacturing Sympathy? New York: Palgrave Macmillan, 2014.

_. "What Should We Expect of 'Erasmus Generations'?” JCMS: Journal of Common Market Studies 49, no.5 (2011): 1113-40. 